\title{
Residential Dampness and Molds and the Risk of Developing Asthma: A Systematic Review and Meta- Analysis
}

\author{
Reginald Quansah', Maritta S. Jaakkola, ${ }^{1,2}$, Timo T. Hugg ${ }^{1,3}$, Sirpa A. M. Heikkinen ${ }^{1,2}$, Jouni J. \\ K. Jaakkola ${ }^{1,3 *}$
}

1 Center for Environmental and Respiratory Health Research, University of Oulu, Oulu, Finland, 2 Respiratory Medicine Unit, Institute of Clinical Medicine, University of Oulu and Oulu University Hospital, Oulu, Finland, $\mathbf{3}$ Institute of Health Sciences, University of Oulu, Oulu, Finland

\begin{abstract}
Context: Studies from different geographical regions have assessed the relations between indoor dampness and mold problems and the risk of asthma, but the evidence has been inconclusive.

Objective: To assess the relations between indicators of indoor dampness and mold problems and the risk of developing new asthma, and to investigate whether such relations differ according to the type of exposure.
\end{abstract}

Data sources: A systematic literature search of PubMed database from 1990 through March 2012 and the reference lists of recent reviews and of relevant articles identified in our search.

Study selection: Cohort/longitudinal and incident case-control studies assessing the relation between mold/dampness and new asthma were included.

Data extraction: Three authors independently evaluated eligible articles and extracted relevant information using a structured form.

Synthesis: Sixteen studies were included: 11 cohort and 5 incident case-control studies. The summary effect estimates (EE) based on the highest and lowest estimates for the relation between any exposure and onset of asthma were $1.50(95 \%$ confidence interval $[\mathrm{Cl}]$ 1.25-1.80, random-effects model, $Q$-statistic $38.74(16), P=0.001)$ and $1.31(95 \% \mathrm{Cl} 1.09-1.58$, random-effects model, $Q$-statistic $40.08(16), P=0.000)$, respectively. The summary effect estimates were significantly elevated for dampness (fixed-effects model: EE 1.33, 95\% Cl 1.12-1.56, $Q$-statistic 8.22 (9), $P=0.413$ ), visible mold (randomeffects model; EE 1.29, 95\% Cl 1.04-1.60, 30.30 (12), $P=0.001$ ), and mold odor (random-effects model; $\mathrm{EE} \mathrm{1.73,95 \%} \mathrm{Cl} \mathrm{1.19-}$ 2.50, Q-statistics 14.85 (8), $P=0.038$ ), but not for water damage (fixed-effects model; $\mathrm{EE} 1.12,95 \% \mathrm{Cl} 0.98-1.27$ ). Heterogeneity was observed in the study-specific effect estimates.

Conclusion: The evidence indicates that dampness and molds in the home are determinants of developing asthma. The association of the presence of visible mold and especially mold odor to the risk of asthma points towards mold-related causal agents.

Citation: Quansah R, Jaakkola MS, Hugg TT, Heikkinen SAM, Jaakkola JJK (2012) Residential Dampness and Molds and the Risk of Developing Asthma: A Systematic Review and Meta-Analysis. PLoS ONE 7(11): e47526. doi:10.1371/journal.pone.0047526

Editor: Thomas Behrens, University of Bochum, Germany

Received August 12, 2012; Accepted September 12, 2012; Published November 7, 2012

Copyright: (c) 2012 Quansah et al. This is an open-access article distributed under the terms of the Creative Commons Attribution License, which permits unrestricted use, distribution, and reproduction in any medium, provided the original author and source are credited.

Funding: This work was funded by the Research Council for Health, the Academy of Finland, grants no. 129419 (SALVE Research Program) and 138691. The funders had no role in study design, data collection and analysis, decision to publish, or preparation of the manuscript.

Competing Interests: The authors have declared that no competing interests exist.

*E-mail: jouni.jaakkola@oulu.fi

\section{Introduction}

Indoor dampness and mold problems are common around the world, being one of the most important indoor problems globally. In cold climate the prevalence of water damage and dampness problems has varied between $5 \%$ and $30 \%$, while in moderate and warm climates the estimates have been between $10 \%$ and $60 \%$ [13]. The prevalence of indoor mold has been $5-10 \%$ in cold climate and $10-30 \%$ in moderate and warm climates [2,3]. Thus, a substantial proportion of the world's population is exposed to dampness-related exposures.
Since the 1990s increasing number of studies from different geographical regions has addressed the health effects related to indoor dampness and mold problems. In 2004 the Institute of Medicine in the USA [4] reported a review of literature and concluded that there is evidence of an association between indoor dampness-related exposures and the following outcomes: upper respiratory tract symptoms, cough, wheeze, and asthma exacerbation. In addition, sufficient evidence was found between mold exposure and hypersensitivity pneumonitis. In a meta-analysis by Fisk and co-workers [5] the risk of current (prevalent) asthma and 
ever-diagnosed (prevalent) asthma were significantly increased in relation to any dampness or molds as a combined exposure, but the results on development of new asthma remained inconclusive, as only four studies had been published by then.

Asthma is the most common chronic disease in children and it is also a common chronic disease in adults with the prevalence of about 7\% in Western countries [6,7]. There has been debate on whether indoor dampness-related exposures can cause asthma, a question which is of major public health and economic importance. If development of asthma could be prevented by prevention or repairing of indoor dampness problems, this could lead to substantial savings in health care costs and improvement in public health. On the other hand, such remediation measures are often expensive, so clear evidence of chronic health effects would justify such investment in the indoor environments. A qualitative review up to late 2009 was published recently by Mendell et al [8], showing that there are new studies published on indoor molds and asthma development. However, they did not conduct any quantitative analysis of the studies.

To address whether studies published up till March 2012 support the hypothesis that indoor dampness and mold problems significantly increase the risk of developing new asthma and to provide a quantitative estimate for these relations, we carried out a systematic review and meta-analysis. In addition, we investigated whether such relations differ according to the type of exposure, by carrying out separate meta-analyses for different exposure indicators, including water damage, dampness, visible mold, and mold odor. Differences according to the type of exposure would give insight into the specific causal agents and pathways and be of importance for preventive actions.

\section{Materials and Methods}

\section{Search strategy}

We performed a systematic literature search of PubMed database from 1990 through March 2012, as described in Figure 1. We further searched the reference lists of recent reviews and of relevant articles identified in our search.

\section{Eligibility criteria and outcome and exposure definitions}

Three authors independently evaluated the articles. Studies that met the following a priori criteria were included: the study (i) was an original study, (ii) was a cohort/longitudinal or an incident casecontrol study, (iii) reported new cases or onset of asthma, (iv) included a study population of children/infants or adults or both, (v) reported on the relations between dampness and/or mold exposure and new asthma, and (vi) reported dampness and/or mold exposure in the home environment. A study was excluded if the study population included asthmatics at baseline (cohort studies) or prevalent cases (case-control studies). If more than one report was published from the same study, the most recent study or the study with the longest follow-up or the study providing best assessment of exposure and/or outcome was included. The outcome of interest was onset of asthma/development of new asthma. The definitions of asthma considered eligible included the doctor-diagnosis, asthma based on lung function measurements, asthma reported by the patient or parent(s)/guardian(s), reported wheezing, and use of asthma medication. The definitions of exposure that were eligible included water damage, damp stains or other dampness indicators, visible mold, and mold odor.

\section{Data extraction and quality assessment}

The eligible studies were examined and the relevant characteristics of each study recorded in our standard data extraction form
[9] independently by the three reviewers. Any disagreements were discussed until a consensus was achieved. Table 1 displays the main characteristics of the eligible studies. The study quality was assessed using the Newcastle-Ottawa Scale (NOS) [10] with the maximum score of 9 . In the main analysis, studies scoring 8 or 9 were categorized as high quality.

\section{Statistical methods}

In the meta-analysis we calculated summary effect estimates (EE) from the study-specific odds ratios (OR) and incidence rate ratios (IRR) by using fixed- and random-effects models [11]. When available, we preferred the adjusted effect estimates over the crude estimates. The summary effect estimate from the fixed-effects model is presented when the study-specific effect estimates were homogeneous, whereas that from the random-effects model is presented when moderate or substantial heterogeneity was observed. Heterogeneity was evaluated using the $Q-$ and $I^{2}$ statistics $\left(I^{2}\right.$-statistic $>50 \%$ indicates high, $25-50 \%$ medium, and $<25 \%$ low heterogeneity). Stratified and meta-regression analyses were performed to elaborate heterogeneity between study-specific effect estimates. The possibility of publication bias was explored with a funnel plot. We used the "metan" command to run the fixed- and random-effects models on Stata 11 (StataCorp LP, College Station, TX, USA) [12].

\section{Results}

\section{Literature search}

A step-by-step approach of the literature search is shown in Figure 1. Sixteen studies [6,13-27] met the a priori inclusion criteria and were included in the systematic review and metaanalysis. Among the 16 articles, 5 were identified from reference lists of relevant studies and 1 from a review by the World Health Organization (WHO) [3]. Thirty-nine articles [28-66] were excluded for reasons given in Table S1. Six of the 16 studies specifically studied the relation between any dampness or mold exposure and onset of asthma, 8 reported on water damage and onset of asthma, 9 on dampness and onset of asthma, 12 on visible mold and onset of asthma, and 8 on mold odor and onset of asthma (Table 2).

\section{Design characteristics of included studies}

Characteristics of the 16 eligible studies are shown in Table 1. Definition of asthma was based on lung function measurements, doctor-diagnosed asthma by clinical examination, reported doctordiagnosis, reporting of asthma attacks and/or the use of asthma medication, and reporting of wheezing and signs of asthma (Table 1).

Information on exposure was reported by home occupants in questionnaires or in an interview or by trained/professional inspectors. The studies defined exposures in variable ways (Table S2) and we systematically categorized them into any exposure, water damage, dampness, visible mold, and mold odor (Table 2). Six of the 16 studies provided effect estimates for the relation between any exposure and onset of asthma. For 10 studies, the effect estimate for 'any exposure' was chosen or calculated based on the effect estimates reported for specific exposure indicators. Analyses were conducted based on both the highest (Table 2) and the lowest effect estimates (Table S3) for specific exposures.

\section{Any exposure and onset of asthma}

Figure 2A shows the forest plot of 16 effect estimates for the relation between any dampness or mold exposure and onset of 




Figure 1. Diagram of the systematic search showing selection of the studies. doi:10.1371/journal.pone.0047526.g001

asthma. The summary effect estimate from the random-effects model was 1.50 (95\% CI 1.25-1.80) based on the highest studyspecific effect estimates (Table S4) and 1.31 (95\% CI 1.09-1.58) based on the lowest effect estimates (Table S5). Substantial heterogeneity was observed in the study-specific effect estimates. We elaborated sources of heterogeneity by conducting stratified analyses (Tables S4 and S5). The summary effect estimate (EE) based on the highest study-specific effect estimates was the highest among infants (1.99), the second highest among children (1.30) and lowest among adults (1.19). The analyses stratified by study design showed only slight differences in the effect estimate based on cohort $(1.36,1.14-1.63)$ vs. incident case-control studies (1.97, 1.19-3.28). The effect estimate based on studies using home inspection for exposure assessment was substantially higher (2.24, 1.47-3.41) compared with the estimate based on studies with selfreported exposure (1.29, 1.11-1.48; Table S4). However, both effect estimates were statistically significant. Exposure assessment remained a significant determinant of heterogeneity also in the meta-regression indicating that it has an important independent role in producing heterogeneity between studies. On the other hand, the fact that the higher quality assessment (home inspection) produces stronger effect estimates strengthens the conclusions about the studied relation. Very limited number of studies provided any measurements of fungi or related compounds, so there was not enough data to carry out a meta-analysis based on them. In meta-regression analysis, infant population $(P=0.086)$, exposure assessment method $(P=0.020)$, and study quality $(P=0.061)$ were determinants of heterogeneity, while climatic zone $(P=0.546)$ or other covariates did not explain heterogeneity.

The funnel plot was moderately asymmetric indicating a possibility of publication bias (Figure S1). Adjustment for publication bias by imputing four "missing" studies using the trim and fill method reduced marginally the strength of the overall summary effect estimate to 1.31 (95\% CI 1.07-1.65). 


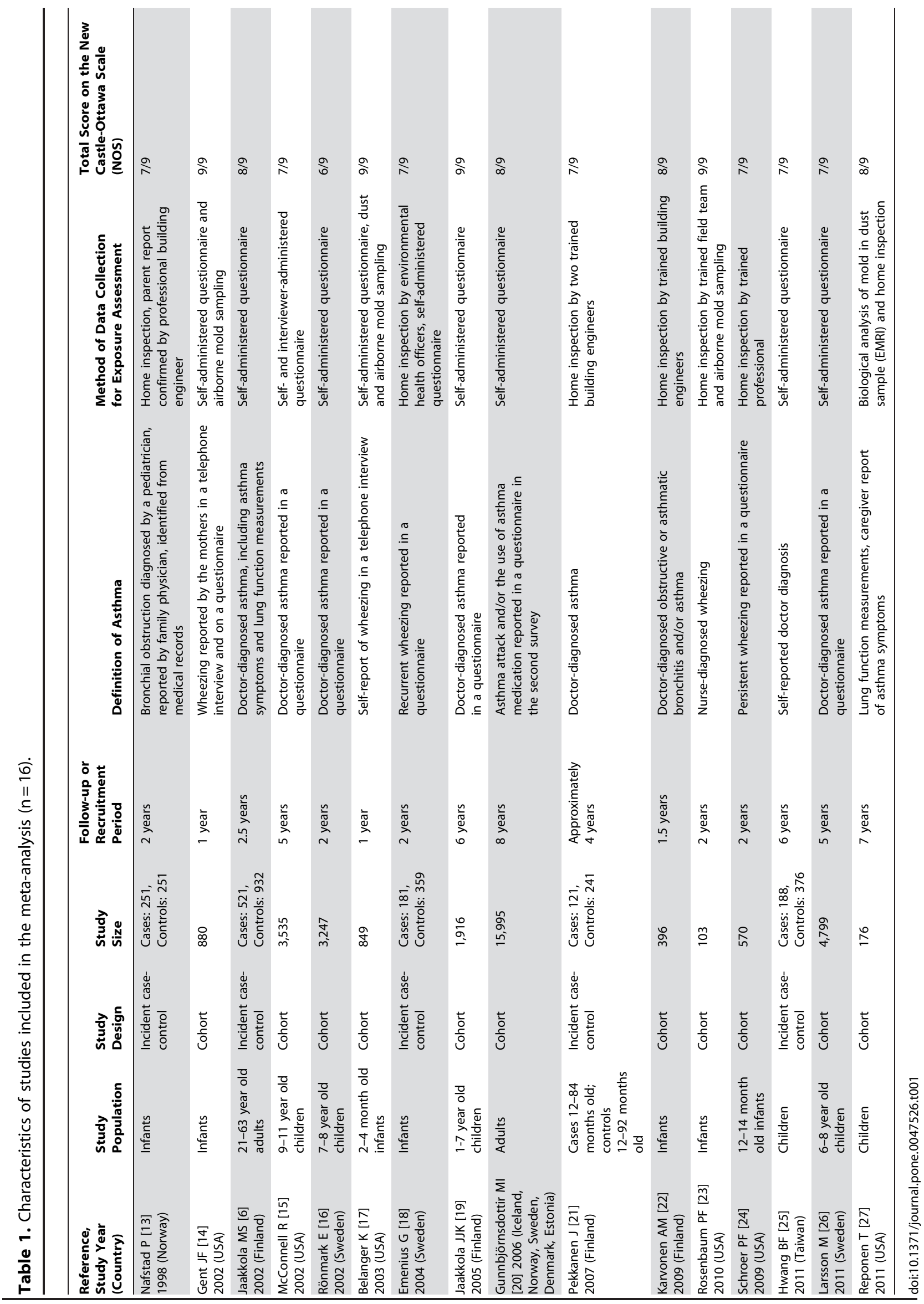


Table 2. Study-specific and summary effect estimates from the studies included in the meta-analysis using the highest effect estimates reported in the studies.

\begin{tabular}{|c|c|c|c|c|c|}
\hline \multirow[t]{2}{*}{ Reference, Year, Country } & \multicolumn{5}{|c|}{ Exposure measures and effect estimates (EE) } \\
\hline & $\begin{array}{l}\text { Any exposure } \\
\text { EE }(95 \% \mathrm{Cl})\end{array}$ & $\begin{array}{l}\text { Water damage } \\
\text { EE }(95 \% \mathrm{Cl})\end{array}$ & $\begin{array}{l}\text { Dampness } \\
\text { EE }(95 \% \mathrm{Cl})\end{array}$ & $\begin{array}{l}\text { Visible mold } \\
\text { EE }(95 \% \mathrm{Cl})\end{array}$ & $\begin{array}{l}\text { Mold odor } \\
\text { EE }(95 \% \mathrm{Cl})\end{array}$ \\
\hline Nafstad P [13] 1998 Norway & $3.8(2.0-7.2)^{b}$ & & & & \\
\hline Gent JF [14] 2002 USA & $1.23(0.94-1.61)^{c}$ & $1.18(0.90-1.55)$ & & $1.23(0.94-1.61)^{\mathrm{a}}$ & \\
\hline Jaakkola MS [6] 2002 Finland & $1.02(0.73-1.41)^{c}$ & $0.90(0.61-1.34)$ & $1.02(0.73-1.41)$ & $0.98(0.68-1.40)$ & $0.98(0.68-1.40)$ \\
\hline McConnell R [15] 2002 USA & $1.08(0.78-1.49)^{c}$ & $1.08(0.78-1.49)$ & & $0.87(0.68-1.12)$ & \\
\hline Rönmark E [16] 2002 Sweden & $1.17(0.58-2.40)^{c}$ & & $1.17(0.58-2.40)$ & & \\
\hline Belanger K [17] 2003 USA & $1.54(1.09-2.18)^{c}$ & & & $1.54(1.09-2.18)$ & \\
\hline Emenius G [18] 2004 Sweden & $2.0(1.20-3.40)^{\mathrm{b}}$ & & $1.50(1.00-2.30)$ & $1.00(0.50-1.70)$ & $2.00(1.00-3.90)$ \\
\hline Jaakkola JJK [19] 2005 Finland* & $1.01(0.66-1.54)^{b}$ & $1.01(0.45-2.26)$ & $0.92(0.54-1.54)$ & $0.65(0.24-1.72)$ & $2.44(1.07-5.60)$ \\
\hline $\begin{array}{l}\text { Gunnbjörnsdottir MI [20] } 2006 \text { (Iceland, } \\
\text { Norway Sweden, Denmark, Estonia) }\end{array}$ & $1.27(1.06-1.52)^{\mathrm{b}}$ & $1.18(0.95-1.44)$ & $1.67(1.22-2.27)$ & $1.53(1.18-1.98)$ & \\
\hline Pekkanen J [21] 2007 Finland & $4.01(1.12-14.32)^{c}$ & & $1.97(1.00-3.90)$ & $4.01(1.12-14.32)$ & $2.96(0.62-14.19)$ \\
\hline Karvonen AM [22] 2009 Finland & $5.22(1.48-18.35)^{c}$ & & $1.29(0.50-3.32)$ & $5.22(1.48-18.35)$ & $0.66(0.14-3.17)$ \\
\hline Rosenbaum PF [23] 2010 USA & $1.32(0.58-3.22)^{c}$ & $1.32(0.58-3.22)^{\mathrm{a}}$ & $1.32(0.58-3.02)^{\mathrm{a}}$ & $0.90(0.35-2.29)^{\mathrm{a}}$ & $1.32(0.58-3.02)^{\mathrm{a}}$ \\
\hline Schroer KT [24] 2009 USA & $2.47(1.27-4.80)^{\mathrm{b}}$ & & & & \\
\hline Hwang BF [25] 2011 Taiwan & $1.69(1.67-2.45)^{b}$ & $2.80(0.59-13.3)$ & & $1.76(1.18-2.26)$ & $2.09(1.30-3.37)$ \\
\hline Larsson M [26] 2011 Sweden $^{\mu}$ & $2.99(1.50-5.94)^{c}$ & $0.93(0.55-1.57)$ & $1.49(0.35-6.30)$ & $1.49(0.35-6.30)$ & $2.99(1.50-5.94)$ \\
\hline Reponen T [27] 2011 USA & $0.88(0.52-1.48)^{c}$ & & & & \\
\hline$Q$ statistics, $P$ value & $38.74,0.001$ & $3.65,0.819$ & $8.22,0.413$ & $30.30,0.001$ & $14.85,0.038$ \\
\hline$I^{2}$-index & 61.3 & 0.0 & 2.6 & 63.7 & 52.9 \\
\hline \multicolumn{6}{|l|}{ Summary Effect Estimate } \\
\hline Fixed-Effects Model & $1.35(1.23-1.49)$ & $1.12(0.98-1.27)$ & $1.33(1.12-1.56)$ & $1.27(1.14-1.41)$ & $1.56(1.25-1.95)$ \\
\hline Random-Effects Model & $1.50(1.25-1.80)$ & $1.12(0.98-1.27)$ & $1.32(1.12-1.57)$ & $1.29(1.04-1.60)$ & $1.73(1.19-2.50)$ \\
\hline
\end{tabular}

\section{Water damage and onset of asthma}

The summary effect estimate for water damage, based on 8 available homogeneous effect estimates (Figure 2B), was slightly, but not significantly elevated (fixed-effects model; EE 1.12, $95 \%$ CI $0.98-1.27)$.

\section{Dampness and onset of asthma}

The relation between dampness indicators and onset of asthma was reported in 9 studies (Figure 2C). The summary effect estimate, based on rather homogeneous study-specific effect estimates, was significantly increased, being 1.33 (fixed-effects model; 95\% CI 1.12-1.56). There was no evidence of publication bias. The stratified analyses are presented in Table S6.

\section{Visible mold and onset of asthma}

Twelve studies estimated the relation between visible mold and onset of asthma (Figure 2D). The meta-analysis based on the highest study-specific effect estimates gave the summary effect estimate of 1.29 (random-effects model; 95\% CI 1.04-1.60). There was no evidence of publication bias. There was substantial heterogeneity between study-specific estimates, but the stratified analysis and meta-regression did not identify any significant determinant of this (Table S7).

\section{Mold odor and onset of asthma}

The relation between mold odor and onset of asthma was reported in 8 studies (Figure 2E). The random-effects model provided a significantly increased summary effect estimate of 1.73 (95\% CI 1.19-2.50). There was no evidence of publication bias. There was substantial between-study variability. In the stratified analyses (Table S8), the effect estimate was higher in studies with long follow-up (1.91) compared to those of shorter duration (1.20) and in studies conducted in continental cool summer zone (EE $1.59,95 \%$ CI $1.01-2.81)$.

\section{Discussion}

This systematic review and meta-analysis clearly demonstrates that the risk of developing asthma is significantly increased in relation to home dampness and molds present prior to the onset of disease. In order to strengthen the causal inference and improve the quantification of the effect size, we focused on the strongest study designs including only cohort and incident case-control studies with new cases of asthma, and therefore assessing exposure that took place prior to the onset/diagnosis of disease. Further we elaborated different exposure indicators which characterize exposure at different points of a hypothesized simplified causal pathway starting from the occurrence of water damage or leakages, followed by the presence of dampness on indoor surfaces 
A



E
B

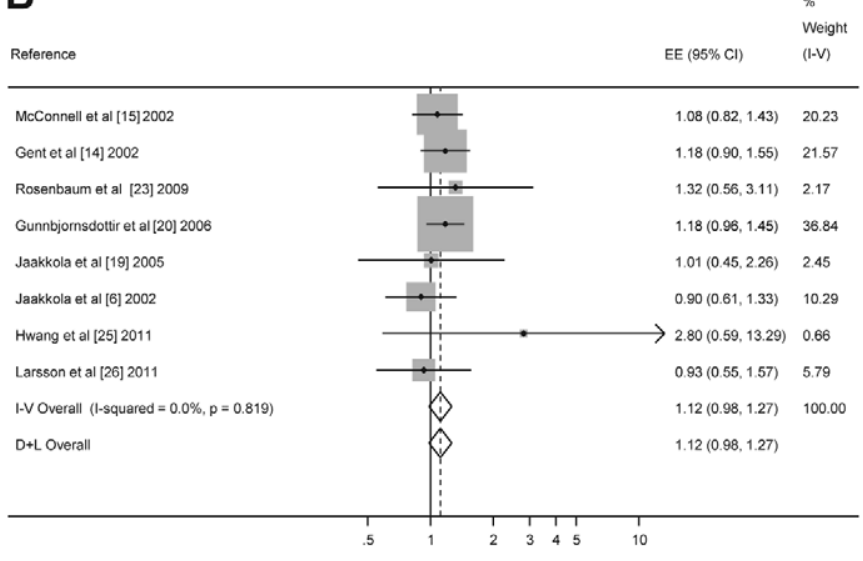

D

$\%$ Weight

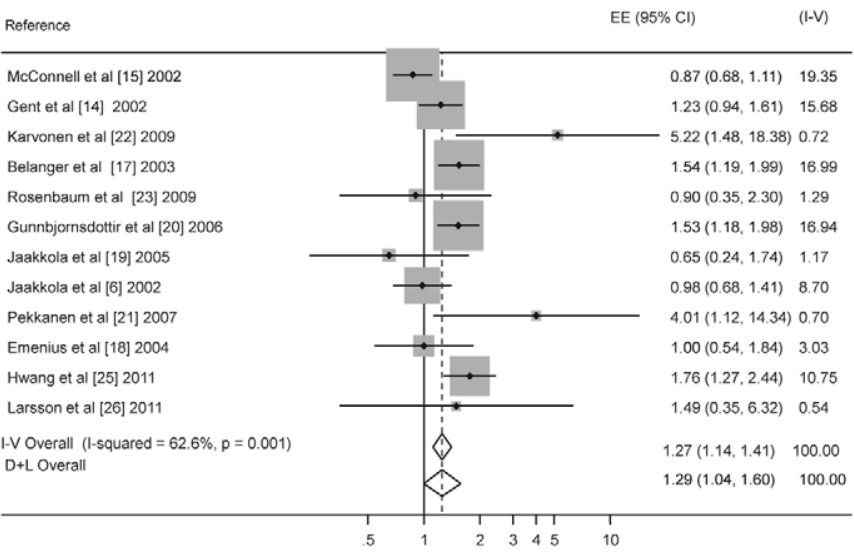
$\%$

Weight

EE $(95 \% \mathrm{Cl}) \quad(\mathrm{I}-\mathrm{V})$

$1.32(0.58,3.01) \quad 6.19$

$2.44(1.07,5.58) \quad 6.15$

$0.98(0.68,1.41) \quad 32.29$

Jaakkola et al [6] 2002

Pekkanen et al [21] 2007

Emenius et al [18] 2004

Hwang et al [25] 2011

Larsson et al [26] 2011

I-V Overall (I-squared $=57.3 \%, p=0.016$ )
D+L Overall

D+L Overall

Drang

Figure 2. Forest plots. A. Forest plot for the relation between any exposure and onset of asthma $(n=16)$. B. Forest plot for the relation between water damage and onset of asthma $(n=8)$. C. Forest plot for the relation between dampness and onset of asthma $(n=9)$. D. Forest plot for the relation between visible mold and onset of asthma $(n=12)$. E. Forest plot for the relation between mold odour and onset of asthma $(n=8)$. doi:10.1371/journal.pone.0047526.g002

and structures, and finally, the presence of visible mold and sensation of mold odor in the home (Figure 3).

To quantify the overall risk we identified or constructed an exposure indicator for any exposure which allowed us to calculate a summary effect estimate based on all 16 eligible epidemiologic studies. The summary effect estimate for any exposure to home dampness or molds indicated an average 50\% increase in the risk of asthma when the highest study-specific effect estimates were applied. The corresponding increase in the risk of asthma was $31 \%$ when the lowest study-specific effect estimates were used. Both estimates were statistically significant. The summary effect estimates related to specific exposures were consistently increased 


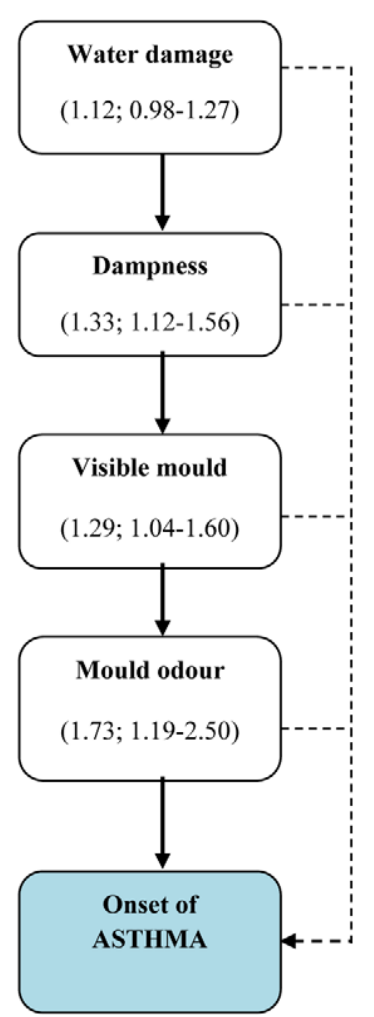

Figure 3. Effect estimates for exposure indicators according to the hypothesized simplified causal pathway. doi:10.1371/journal.pone.0047526.g003

mold odor (an average 73\% increase in the risk of asthma), visible mold (29\% increase) and dampness (33\% increase), while the asthma risk was not significantly increased in relation to water damage per se. Interestingly, the exposure assessment based on inspection produced higher risk estimates than self-reports, suggesting that study subjects tend to underestimate their exposure to indoor dampness and mold problems.

\section{Validity of results}

The strengths of our study include selection of individual studies based on a clearly defined search strategy. In addition to the primary PubMed search, we also used secondary references that were cited by the articles and reviews identified in the primary search. Three reviewers checked independently the eligibility of the studies according to a priori set inclusion and exclusion criteria and decided on the most appropriate effect estimate. Any disagreements were settled by discussion.

The present systematic review focused on epidemiological studies with strong design including only cohort and incident case-control studies, and therefore all cross-sectional studies were excluded. This was because we wanted to address the study question whether indoor dampness and mold problems are related to development of new asthma, a question that has remained open in previous reviews.

We evaluated the possibility of publication bias using funnel plots and 'metarim' method for simulating any asymmetry appearing in funnel plots. There was an indication of slight publication bias when addressing the effect of any dampnessrelated exposure. However, addition of four studies to eliminate the asymmetry of the funnel plot using the trim and fill method reduced the strength of the overall effect estimate marginally from 1.50 to 1.31 , but the effect remained statistically significant $(95 \%$
CI 1.07-1.65). Publication bias diagnostics for the four specific exposure indicators showed no suggestion of publication bias.

\section{Synthesis with previous knowledge}

One previous meta-analysis [5] has addressed the relations between any exposure to indoor dampness or molds and asthma, but it focused on prevalent asthma, i.e. ever-diagnosed asthma or current asthma, finding a significant excess risk of 37-56\%. Our summary effect estimate for the relation between any dampness or mold and onset of asthma was 1.50 based on the highest reported estimates and 1.31 based on the lowest reported estimates. Interestingly the estimated excess risk was most consistent and highest in relation to mold odor at home, with an excess risk of $73 \%$. This could mean that mold odor is the most specific exposure related to asthma, as it typically refers to microbial contamination of indoor space. Being able to smell odor indicates that there is a connection between the damaged area and the breathing zone of people occupying that space. It also usually reflects long-term exposure to dampness, as it takes some time until there is enough microbial growth to produce enough chemical compounds to be sensed as odor. A study [50] from USA investigated asthma that was diagnosed by a physician after the employees had worked in a large office building with a history of water damage. They measured microbes in floor dust and found significantly increased risk of asthma in relation to exposure to hydrophilic fungi, with an OR 2.19 (95\% CI 1.23-3.89), as well as in relation to yeast exposure, with an OR1.77 (95\% CI 1.05-3.01), supporting the hypothesis that indoor microbial growth plays a major role in the development of asthma. In our meta-analysis, visible mold was also significantly related to an increased risk of developing asthma, although the effect estimate was somewhat lower (EE 1.29, 95\% CI 1.04-1.60) than the estimate for mold odor (EE 1.73, 95\% CI 1.19-2.50) and there was more heterogeneity. A population-based incident case-control study from Finland [6] showed a significantly increased risk of adultonset asthma in relation to visible mold or mold odor at work, with an OR of 1.54 (95\% CI 1.01-2.32), which is in line with our findings related to home exposure.

Toxicologic studies have suggested plausible biologic mechanisms demonstrating inflammatory, cytotoxic and immunosuppressive responses to exposure to spores, and metabolites and components of different microbial species. These were recently reviewed by WHO Europe [3] and Mendell et al [8]. It has been suggested that different species of microbes have their effect through different mechanisms, including an IgE-mediated hypersensitivity reaction [34], other immunologic reactions, cytotoxic reactions, and irritant inflammatory effects caused by cell wall components, such as 1,3-B-D-glucan, endotoxins and extracellular polysaccharides $[1,2,19,57,67-69]$.

Exposure to dampness indicators was related to a smaller, but still significant risk of developing asthma with an effect size of 1.33 (95\% CI 1.12-1.56). This may reflect a less extensive damage or a damage of shorter duration, or the role of other exposures than microbes. Several potential causal factors have been suggested to play a role for asthma in relation to dampness problems, including house dust mites and chemicals emitted from damp materials in addition to mold and bacterial growth [2,19,70-73].

Water damage per se was not related to an excess risk of developing asthma (summary effect estimate; 1.12 , 95\% CI $0.98-$ 1.27) in our meta-analysis, which is logical considering that the first step in the causal pathway starts with the water damage with no specific causal exposures at the beginning (Figure 3). With a prolonged dampness problem potential causal agents emerge, including microbes, house dust mites, and chemical emissions. 
Overall our results provide evidence that indoor dampness and mold problems are related to development of the chronic disease condition asthma, which gives weight to the need for preventive and remediation actions. Indeed, our results give ground for the recommendation by a recent expert review suggesting that an intervention of 'combined elimination of moisture intrusion and leaks and removal of moldy items' is effective for reducing health risks to occupants $[8,74]$.

\section{Conclusions}

The evidence up to date from the most valid studies indicates that dampness and mold in the home are determinants of developing asthma. The association of the presence of visible mold and especially mold odor to the risk of asthma points towards mold-related causal agents. Home dampness may also be related to other indoor environmental factors, such as dust mites and chemical emissions from damp structures and surface materials, which may be other causal agents related to development of asthma. Our results provide evidence that justifies prevention and remediation of indoor dampness and mold problems and such actions are likely to reduce induction of new asthma, lead to savings in the health care costs and improvement of public health.

\section{Supporting Information}

Figure S1 Funnel plot for the relation between any exposure and the onset of asthma (based on the highest effect estimates reported in the studies). (DOCX)

Table S1 Studies identified in the search but excluded from the meta-analysis $(\mathrm{n}=39)$.

(DOCX)

\section{References}

1. Jaakkola MS, Jaakkola JJK (2004) Indoor molds and asthma in adults. Adv Appl Microbiol 55: 309-338.

2. Jaakkola MS, Haverinen-Shaugnessy U, Doewes J, Nevalainen A (2011) Indoor dampness and mold problems in homes and asthma onset in children. In: Braubach M, Jacobs DE, Ormandy D, editors. Environmental burden of disease associated with inadequate housing-A method guide to the quantification of health effects of selected housing risks in the WHO European Region. Geneva: World Health Organization.

3. World Health Organization (WHO) Europe (2009) WHO Guidelines for Indoor Air Quality: dampness and mold. Copenhagen: World Health Organization. Available: http://www.euro.who.int/_data/assets/pdf_file/0017/43325/ E92645.pdf. Accessed $2011 \mathrm{Jul} 14$.

4. Institute of Medicine (IOM) (2004) Damp indoor spaces and health. Washington, DC: National Academies Press. Available: http://www.iom. edu/.../Damp-Indoor-Spaces-and-Health.aspx. Accessed 2011 Aug 1.

5. Fisk WJ, Lei-Gomez Q Mendell MJ (2007). Meta-analyses of associations of respiratory health effects with dampness and mold in homes. Indoor Air 17: 284-296.

6. Jaakkola MS, Nordman H, Piipari R, Uitti J, Laitinen J, et al. (2002) Indoor dampness and molds and development of adult-onset asthma: a populationbased incident case-control study. Environ Health Perspect 110: 543-547.

7. Moorman JE, Zahran H, Truman BI, Molla MT (2011) Current asthma prevalence - United States, 2006-2008. MMWR Surveill Summ 60 Suppl: 84 86.

8. Mendell MJ, Mirer AG, Cheung K, Tong M, Douwes J (2011) Respiratory and allergic health effects of dampness, mold, and deampness-related agents: A review of epidemiologic evidence. Environ Health perspect 119: 748-756.

9. Alavaikko S, Jaakkola MS, Tjäderhane L, Jaakkola JJK (2011) Asthma and caries: a systematic review and meta-analysis. Am J Epidemiol 174: 631-641.

10. Wells G, Shea B, O'Connell D, Peterson J, Welch V, et al. (2011) The Newcastle-Ottawa Scale (NOS) for assessing the quality if nonrandomized studies in meta-analyses. Available: http://www.ohri.ca/programs/clinical_ epidemiology/oxford.htm. Accessed 2011 Aug 1.
Table S2 Definition or description of exposure in the original studies included in the meta-analysis (arranged in the order as classified in Table 2: $\mathrm{n}=16$ ).

(DOCX)

Table S3 Effect estimates reported in the studies included in the meta-analysis (the lowest effect estimates reported in the studies). (DOCX)

Table S4 Summary effect estimates (EEs) for the relation between any exposure (including the highest effect estimates in the studies) and the risk of asthma onset $(n=16)$ and stratified analysis according to the study characteristics.

\section{(DOCX)}

Table S5 Summary effect estimates (EEs) for the relation between any exposure (including the lowest effect estimates in the studies) and the risk of asthma onset $(n=16)$ and stratified analysis according to the study characteristics.

(DOCX)

Table S6 Summary effect estimates (EEs) for the relation between dampness and the risk of asthma onset $(n=9)$ and stratified analysis according to the study characteristics.

(DOCX)

Table S7 Summary effect estimates (EEs) for the relation between visible mold and the risk of asthma onset $(n=12)$ and stratified analysis according to the study characteristics.

(DOCX)

Table S8 Summary effect estimates (EEs) for the relation between mold odor and the risk of asthma onset $(n=8)$ and stratified analysis according to the study characteristics.

(DOCX)

\section{Author Contributions}

Conceived and designed the experiments: JJ. Performed the experiments: TH SH. Analyzed the data: RQJJ. Wrote the paper: RQ MJ JJ.

11. Borenstein M, Hedges LV, Higgins JPT, Rothstein HR (2009) Introduction to Meta-Analysis. New York, NY: JohnWiley and Sons, Inc.

12. StataCorp (2009) Stata Statistical Software: Release 11. College Station, TX: StataCorp LP.

13. Nafstad P, Øie L, Mehl R, Gaarder PI, Lødrup-Carlsen KC, et al. (1998) Residential dampness problems and symptoms and signs of bronchial obstruction in young Norwegian children. Am J Respir Crit Care Med 157: 410-414.

14. Gent JF, Ren P, Belanger K, Triche E, Bracken MB, et al. (2002) Levels of household mold associated with respiratory symptoms in the first year of life in a cohort at risk for asthma. Environ Health Perspect 110: 781-786.

15. McConnell R, Berhane K, Gilliland F, Islam T, Gauderman WJ, et al. (2002) Indoor risk factors for asthma in a prospective study of adolescents. Epidemiology 13: 288-295.

16. Rönmark E, Perzanowski M, Platts-Mills T, Lundbäck B (2002) Incidence rates and risk factors for asthma among school children: a 2-year follow-up report from the obstructive lung disease in Northern Sweden (OLIN) studies. Respir Med 96: 1006-1013.

17. nger K, Beckett W, Triche E, Bracken MB, Holford T, et al. (2003) Symptoms of wheeze and persistent cough in the first year of life: associations with indoor allergens, air contaminants, and maternal history of asthma. Am J Epidemiol 158: $195-202$

18. Emenius G, Svartengren M, Korsgaard J, Nordvall L, Pershagen G, et al. (2004) Indoor exposures and recurrent wheezing in infants: a study in the BAMSE cohort. Acta Paediatr 93: 899-905.

19. Jaakkola JJK, Hwang BF, Jaakkola N (2005) Home dampness and molds, parental atopy, and asthma in childhood: a six-year population-based cohort study. Environ Health Perspect 113: 357-361.

20. Gunnbjörnsdóttir MI, Franklin KA, Norbäck D, Björnsson E, Gislason D, et al. (2006) Prevalence and incidence of respiratory symptoms in relation to indoor dampness: the RHINE study. Thorax 61: 221-225.

21. Pekkanen J, Hyvärinen A, Haverinen-Shaughnessy U, Korppi M, Putus T, et al. (2007) Moisture damage and childhood asthma: a population-based incident case-control study. Eur Respir J 29: 509-515. 
22. Karvonen AM, Hyvärinen A, Roponen M, Hoffmann M, Korppi M, et al. (2009) Confirmed moisture damage at home, respiratory symptoms and atopy in early life: a birth-cohort study. Pediatrics 12: 329-338.

23. Rosenbaum PF, Crawford JA, Anagnost SE, Wang CJ, Hunt A, et al. (2010) Indoor airborne fungi and wheeze in the first year of life among a cohort of infants at risk for asthma. J Expo Sci Environ Epidemiol 20: 503-515.

24. Schroer KT, Biagini Myers JM, Ryan PH, LeMasters GK, Bernstein DI, et al. (2009) Associations between multiple environmental exposures and Glutathione STransferase P1 on persistent wheezing in a birth cohort. J Pediatr 154: 401-408.

25. Hwang BF, Liu IP, Huang TP (2011) Molds, parental atopy and pediatric incident asthma. Indoor Air 21: 472-478.

26. Larsson M, Hägerhed-Engman L, Moniruzzaman S, Janson S, Sundell J, et al. (2011) Can we trust cross-sectional studies when studying the risk of moisturerelated problems indoor for asthma in children? Int J Environ Health Res 21: 237-247.

27. Reponen T, Vesper S, Levin L, Johansson E, Ryan P, et al. (2011) High environmental relative moldiness index during infancy as a predictor of asthma at 7 years of age. Ann Allergy Asthma Immunol 107: 120-126.

28. Lee YL, Hsiue TR, Lee CH, Su HJ, Guo YL (2006) Home exposures, parental atopy, and occurrence of asthma symptoms in adulthood in southern Taiwan. Chest 129: 300-308.

29. Salo PM, Arbes SJJr, Sever M, Jaramillo R, Cohn RD, et al. (2006) Exposure to Alternaria alternata in US homes is associated with asthma symptoms. J Allergy Clin Immunol 118: 892-898.

30. Dales RE, Zwanenburg H, Burnett R, Franklin CA (1991) Respiratory health effects of home dampness and molds among Canadian children. Am J Epidemiol 134: 196-203.

31. Torén K, Ekerljung L, Kim JL, Hillström J, Wennergren G, et al. (2011) Adultonset asthma in west Sweden-incidence, sex differences and impact of occupational exposures. Respir Med 105: 1622-1628.

32. Matheson MC, Abramson MJ, Dharmage SC, Forbes AB, Raven JM, et al. (2005) Changes in indoor allergen and fungal levels predict changes in asthma activity among young adults. Clin Exp Allergy 35: 907-913.

33. Douwes J, van Strien R, Doekes G, Smit J, Kerkhof M, et al. (2006) Does early indoor microbial exposure reduce the risk of asthma? The Prevention and Incidence of Asthma and Mite Allergy birth cohort study. J Allergy Clin Immunol 117: 1067-1073.

34. Jaakkola MS, Ieromnimon A, Jaakkola JJK (2006) Are atopy and specific IgE to mites and molds important for adult asthma? Allergy Clin Immunol 117: 642 648 .

35. Raphoz M, Goldberg MS, Garneau M, Héguy L, Valois MF, et al. (2010) Associations between atmospheric concentrations of spores and emergency department visits for asthma among children living in Montreal. Arch Environ Occup Health 65: 201-210.

36. Klinnert MD, Nelson HS, Price MR, Adinoff AD, Leung DY, et al. (2001) Onset and persistence of childhood asthma: predictors from infancy. Pediatrics 108: 18 .

37. Kozyrskyj AL, Bahreinian S, Azad MB (2011) Early life exposures: impact on asthma and allergic disease. Curr Opin Allergy Clin Immunol 11: 400-406.

38. Leander M, Cronqvist A, Janson C, Uddenfeldt M, Rask-Andersen A (2009) Health-related quality of life predicts onset of asthma in a longitudinal population study. Respir Med 103: 194-200.

39. Immonen J, Meklin T, Taskinen T, Nevalainen A, Korppi M (2001) Skin-prick test findings in students from moisture- and mould-damaged schools: a 3-year follow-up study. Pediatr Allergy Immunol 12: 87-94.

40. Jaakkola MS, Laitinen S, Piipari R, Uitti J, Nordman H, et al. (2002) Immunoglobulin $\mathrm{G}$ antibodies against indoor dampness-related microbes and adult-onset asthma: a population-based incident case-control study. Clin Exp Immunol 129: 107-112.

41. Halonen M, Stern DA, Wright AL, Taussig LM, Martinez FD (1997) Alternaria as a major allergen for asthma in children raised in a desert environment. Am J Respir Crit Care Med 155: 1356-1361.

42. Korhonen K, Mähönen S, Hyvärinen A, Nevalainen A, Husman T, et al. (2006) Skin test reactivity to molds in pre-school children with newly diagnosed asthma. Pediatr Int 48: 577-581.

43. Karvala K, Toskala E, Luukkonen R, Lappalainen S, Uitti J, et al. (2010) Newonset adult asthma in relation to damp and moldy workplaces. Int Arch Occup Environ Health 83: 855-865.

44. Karvala K, Toskala E, Luukkonen R, Uitti J, Lappalainen S, et al. (2011) Prolonged exposure to damp and moldy workplaces and new-onset asthma. Int Arch Occup Environ Health 84: 713-721.

45. Dales R, Ruest K, Guay M, Marro L, Miller DJ (2010) Residential fungal growth and incidence of acute respiratory illness during the first two years of life. Environ Res 110: 692-698.

46. Stark PG, Burge HA, Ryan LM, Milton DK, Gold DR (2003) Fungal levels in the home and lower respiratory tract illnesses in the first year of life. Am J Respir Crit Care Med 168: 232-237.

47. Stark PC, Celedón JC, Chew GL, Ryan LM, Burge HA, et al. (2005) Fungal levels in the home and allergic rhinitis by 5 years of age. Environ Health Perspect 113: 1405-1409.

48. Sahlberg B, Mi YH, Norbäck D (2009) Indoor environment in dwellings, asthma, allergies, and sick building syndrome in the Swedish population: a longitudinal cohort study from 1989 to 1997. Int Arch Occup Environ Health 82: $1211-1218$.
49. Norbäck D, Zock JP, Plana E, Heinrich J, Svanes C, et al. (2011) Lung function decline in relation to mould and dampness in the home: the longitudinal European Community Respiratory Health Survey ECRHS II. Thorax 66: 396401.

50. Park JH, Cox-Ganser JM, Kreiss K, White SK, Rao GY (2008) Hydrophilic fungi and ergosterol associated with respiratory illness in a water-damaged building. Environ Health Perspect 116: 45-50.

51. Hägerhed-Engman L, Sigsgaard T, Samuelson I, Sundell J, Janson S, et al. (2009) Low home ventilation rate in combination with moldy odor from the building structure increase the risk for allergic symptoms in children. Indoor Air 19: 184-192.

52. Lindfors A, Wickman M, Hedlin G, Pershagen G, Rietz H, et al. (1995) Indoor environmental risk factors in young asthmatics: a case-control study. Arch Dis Child 73: 408-412.

53. Bundy KW, Gent JF, Beckett W, Bracken MB, Belanger K, et al. (2009) Household airborne Penicillium associated with peak expiratory flow variability in asthmatic children. Ann Allergy Asthma Immunol 103: 26-30.

54. Pongracic JA, O'Connor GT, Muilenberg ML, Vaughn B, Gold DR, et al. (2010) Differential effects of outdoor versus indoor fungal spores on asthma morbidity in inner-city children. J Allergy Clin Immunol 125: 593-599.

55. Nguyen T, Lurie M, Gomez M, Reddy A, Pandya K, et al. (2010) The National Asthma Survey-New York State: association of the home environment with current asthma status. Public Health Rep 125: 877-887.

56. Jedrychowski W, Maugeri U, Zembala M, Flak E, Camman D, et al. (2007) Risk of wheezing associated with house-dust mite allergens and indoor air quality among three-year-old children. Kraków inner city study. Int J Occup Med Environ Health 20: 117-126.

57. Tischer C, Gehring U, Chen CM, Kerkhof M, Koppelman G, et al. (2011) Respiratory health in children, and indoor exposure to $(1,3)-3$-D-glucan, EPS mould components and endotoxin. Eur Respir J 37: 1050-1059.

58. Mommers M, Jongmans-Liedekerken AW, Derkx R, Dott W, Mertens P, et al (2005) Indoor environment and respiratory symptoms in children living in the Dutch-German borderland. Int J Hyg Environ Health 208: 373-381.

59. Thorn J, Brisman J, Torén K (2001) Adult-onset asthma is associated with selfreported mold or environmental tobacco smoke exposures in the home. Allergy 56: 287-292.

60. Chen YC, Tsai CH, Lee YL (2011) Early-life indoor environmental exposures increase the risk of childhood asthma. Int J Hyg Environ Health 215: 19-25.

61. Iossifova YY, Reponen T, Ryan PH, Levin L, Bernstein DI, et al. (2009) Mold exposure during infancy as a predictor of potential asthma development. Ann Allergy Asthma Immunol 102: 131-137.

62. Iossifova YY, Reponen T, Bernstein DI, Ryan PH, Levin L, et al. (2007) House dust (1-3)-beta-D-glucan and wheezing in infants. Allergy 62: 504-513.

63. Vesper SJ, McKinstry C, Haugland RA, Iossifova Y, Lemasters G, et al. (2007) Relative moldiness index as predictor of childhood respiratory illness. J Expo Sci Environ Epidemiol 17: 88-94.

64. Cho SH, Reponen T, LeMasters G, Levin L, Huang J, et al. (2006) Mold damage in homes and wheezing in infants. Ann Allergy Asthma Immunol 97: 539-545.

65. Wickman M, Gravesen S, Nordvall SL, Pershagen G, Sundell J (1992) Indoor viable dust-bound microfungi in relation to residential characteristics, living habits, and symptoms in atopic and control children. J Allergy Clin Immunol 89: $752-759$.

66. Hyvärinen A, Sebastian A, Pekkanen J, Korppi M, Putus T, et al. (2006) Characterizing microbial exposure with ergosterol, 3-hydroxy fatty acids, and viable microbes in house dust: determinants and association with childhood asthma. Arch Environ Occup Health 61: 149-157.

67. Giovannangelo ME, Gehring U, Nordling E, Oldenwening M, van Rijswijk K, et al. (2007) Levels and determinants of beta $(1->3)$-glucans and fungal extracellular polysaccharides in house dust of (pre-)school children in three European countries. Environ Int 33: 9-16.

68. Gehring U, Heinrich J, Hoek G, Giovannangelo M, Nordling E, et al. (2007) Bacteria and mould components in house dust and children's allergic sensitisation. Eur Respir J 29: 1144-1153.

69. Douwes J, Zuidhof A, Doekes G, van der Zee SC, Wouters I, et al. (2000) (1$>3$ )-beta-D-glucan and endotoxin in house dust and peak flow variability in children. Am J Respir Crit Care Med 162: 1348-1354.

70. Jaakkola JJK, Quansah R (2010) Building materials, furnishing and health. In: Tarlo S, Nemery B, Cullinan P, editors. Environmental and Occupational Lung Diseases. Hoboken, NJ: John Wiley and Sons Ltd. p. 69-79.

71. Bornehag CG, Sundell J, Sigsgaard T (2004) Dampness in buildings and health $(\mathrm{DBH})$ : report from an ongoing epidemiological investigation on the association between indoor environmental factors and health effects among children in Sweden. Indoor Air 14: 59-66.

72. Bornehag CG, Sundell J, Weschler CJ, Sigsgaard T, Lundgren B, et al. (2004) The association between asthma and allergic symptoms in children and phtalates in house dust: a nested case-control study. Environ Health Perspect 112: 13931397.

73. Jaakkola JJK, Knight TL (2008) The role of exposure to phthalates from polyvinyl chloride products in the development of asthma and allergies: a systematic review and meta-analysis. Environ Health Perspect 116: 845-853.

74. Krieger J, Jacobs DE, Ashley PJ, Baeder A, Chew GL, et al. (2010) Housing interventions and control of asthma-related indoor biologic agents: a review of the evidence. J Public Health Manag Pract 16: 11-20. 